\title{
REVISTA LITERATURA E AUTORITARISMO LITERATURA, MÚSICA E O TESTEMUNHO DE RESISTÊNCIA
}

A relação com a resistência no âmbito dos estudos literários aborda uma situação que, por vezes, ainda é tratada de forma conflitiva. Um conflito que não se relaciona com a oposição de ideias ou mesmo como oportunidade para que sejam pensadas novas visões acerca da sociedade e do devir histórico, mas com uma noção que empobrece a potencialidade da crítica literária ao renegá-la ao campo dos aspectos formais quando desconsidera as questões temáticas que norteiam e embasam a criação artística.

A própria publicação da Revista Literatura e Autoritarismo evidencia essa aproximação entre os aspectos éticos e estéticos, mediados pelo viés de um pensamento filosófico e científico capaz de interagir nesses campos que se complementam. Quando Alfredo Bosi destacou que a resistência é - originariamente - um conceito ético e não estético, certamente não estava buscando seu distanciamento do estético, mas a responsabilidade que envolve pensar sua dinâmica para que a arte não deixasse de se fazer presente no momento em que "resistir" se torna urgente, quase como um sinônimo de "existir" em um mundo de opressão, em realidades autoritárias que se alimentam da ignorância e do ódio.

Literatura de resistência se aproxima, nessa linha de raciocínio, da literatura de testemunho, ou melhor, faz com que essas reflexões dialoguem com base em um exercício de sobrevivência, se não do próprio corpo, ao menos do espírito como registro de uma época, de uma (re)existência. Cabe destacar que o artista é a testemunha do seu tempo, conforme a reflexão de Hannah Arendt, e o seu papel é sempre de ressignificar o existir e o resistir. Nesse sentido, os artigos aqui publicados transitam entre gêneros (narrativos e líricos) e artes (literatura e música) com o intuito de abordar a peculiaridade entre o que se convencionou classificar como literatura de testemunho, o testemunho propiciado pelo fazer artístico em seu viés crítico e a resistência que não ignora a ética própria da arte, enfatizando a denúncia à opressão, à violência e ao preconceito.

É relevante destacar que toda a violência está alicerçada em um preconceito, em um índice de fascismo que cada sociedade elabora como base em sua própria constituição, segundo os estudos sobre a personalidade autoritária desenvolvidos por Theodor Adorno após a II Guerra Mundial. Também é de fundamental importância a análise das formas de resistência a partir de Foucault, especialmente as contracondutas que se originam de crises de governabilidade e também de desconfianças em relação à dubiedade da própria organização social estabelecida: se, por um lado, as contradições acabam gerando um posicionamento crítico exigindo transformações, por outro lado, também ocorre o sufocamento desse discurso de resistência em prol da garantia da lei e da ordem social. Os textos aqui disponibilizados salientam esse primeiro lado sem, no entanto, serem ingênuos em relação ao autoritarismo e suas estruturas consolidadas de poder.

O primeiro artigo é de autoria de Filipe da Silva Moreira e Pedro Teixeira Castilho e se propõe a relacionar a literatura com a música popular. Com o título de Do verso ao berro: 
vozes de resistências frente ao projeto civilizatório brasileiro nos campos da literatura e da música popular, o percurso histórico da formação da sociedade brasileira é percorrido com base em uma crítica a um processo civilizatório que renegou a maior parte dessa sociedade à condição de inviabilidade, deixando-a vulnerável aos ditames do poder. "Nesse sentido, as proposições de Luiz Gama e Alberto Nepomuceno na construção de uma linguagem decolonial tornam, nas obras de Evaristo e no surgimento do Rap nacional, ecos de uma voz agora potencializada pela condição social desfavorável e pela transformação da relação do indivíduo com a cultura, considerando o advento da hipermodernidade."

Luciana Paiva Coronel é autora do texto Literatura marginal: a genealogia de uma escrita de resistência. Ao buscar entender as raízes da literatura marginal no Brasil atual, as abordagens retrocedem ao início do século XX e ao contexto político da República enquanto conceito que ainda permanece um tanto obscuro na sociedade brasileira, especialmente quando visto pela periferia e por quem está à margem da nação e da cidadania. Luciana Paiva Coronel argumenta que a literatura marginal inaugura no século XXI "a perspectiva da margem como locus inédito de enunciação literária no país. Não por meio de uma separação segregadora de si em um gueto, mas por meio de um rótulo de diferenciação que evidenciaria, segundo seu criador, a divisão existente na sociedade, que seria replicada no âmbito da criação literária, independente da vontade de seus protagonistas."

$\mathrm{O}$ artigo seguinte, intitulado Literatura marginal como projeto de resistência: uma leitura a partir de três romances de Ferréz, de autoria de Ricardo José dos Santos Neto, representa uma contribuição significativa para a discussão sobre a literatura marginal e um de seus grandes nomes: Reginaldo Ferreira da Silva, o Ferréz. A partir da leitura e análise dos romances Capão pecado (2000), Manual prático do ódio (2003) e Deus foi almoçar (2012), o autor conclui que "[a] marginalidade em Ferréz pode, também, ser vista como foco de resistência. Essa se mostra na postura do escritor ao sistema hegemônico literário por meio do uso da linguagem bem próxima à oralidade; pelos espaços geográficos em que se delineiam seus romances - favelas, bairros pobres, setores urbanos que estão postos à margem das cidades; pelos personagens, sujeitos marginalizados, que em geral são estereotipados ou desumanizados pela literatura, ou pela sociedade, sujeitos os quais, quase sempre, se encontram em situação de precariedade e/ou vulnerabilidade."

Rock e resistência na América Latina é o próximo artigo publicado nesta edição, de autoria de Gérson Werlang, e apresenta um olhar sobre o contexto das décadas de 1960 e 1970 na América Latina, especialmente nos contextos das ditaduras militares no Brasil, na Argentina e no Chile nos quais as resistências se multiplicaram para fazer frente às várias formas de opressão, desde a política até a apologia aos valores morais e bons costumes que estavam sendo ameaçados pela juventude da época. Estabelecendo suas análises a partir do conceito de contracultura, Werlang enfatiza o sentido primeiro do rock enquanto contestação, dando atenção aos aspectos que refletiram um posicionamento social contrário ao racismo e de resistência em meio à censura. O autor do ensaio indaga sobre a reação dos grupos de rock a uma ditadura conversadora e repressiva, respondendo que "Com música e letras que tentavam driblar a censura ao mesmo tempo em que apontavam caminhos, numa linguagem muitas vezes altamente figurada. Mas, aqui cabe uma observação, não apenas a letra era revolucionária, também a música. As características do rock brasileiro do período 
contêm uma atitude outsider, regida pelos atos desviantes que desterritorializam e reinventam os sons, fugindo da cultura de massas e provocando uma nova forma artística."

De autoria de Camila Marcelina Pasqual, o artigo 'Pilatos', de Carlos Heitor Cony: uma escrita de resistência desenvolve um estudo sobre as estratégias da escrita de resistência de Carlos Heitor Cony presentes no romance Pilatos publicado em 1974. Considera, a partir de Malcolm Silverman, que a obra pode ser pensada como uma sátira política absur$d a$, marcada por uma linguagem insólita, grotesca e escatológica. Pasqual argumenta que "Cony traz em Pilatos, por intermédio da voz do narrador, um homem com pênis decepado, uma crítica sarcástica que aponta para a castração da liberdade de expressão, principalmente no meio intelectual. Além da castração da liberdade, o autor também se valeu da metáfora da castração em sua escrita para resistir às formas de opressão e confundir os censores da época, para que sua produção ficcional conseguisse passar pelo crivo dos censores."

$\mathrm{O}$ artigo de Danielle Fullan intitulado Memórias do exílio e o testemunho como resistência também aborda o período da ditadura civil-militar brasileira e o processo de reconstrução de uma memória com base em fragmentos do passado que não são acessíveis ao conjunto da sociedade. Iniciando com uma reflexão sobre o conceito de resistência e sua relação com a representação literária, Fullan apresenta um "projeto coletivo que reúne testemunhos de brasileiros que atuaram na resistência à opressão e que, por isso, precisaram partir para o exílio." O livro Memórias do Exílio, Brasil 1964- 19??: De muitos caminhos, publicado em 1976, já deixa claro um posicionamento ao problematizar o término do período ditatorial que oficialmente ocorreu em 1985, mas que outros críticos defendem que se estendeu até, pelo menos, 1989 com as eleições diretas para presidente da república. Além disso, o questionamento aborda a necessidade de ainda hoje a resistência ser vista como dentro de um contexto de opressão do Estado sobre seus cidadãos. Para sustentar suas análises, a pesquisadora recorre à Walter Benjamin e Eurídice Figueiredo para afirmar que "apenas a ficção, por meio da liberdade composicional, pode evocar algo pensado, evocado, sentido ou sofrido por seus personagens diante da impossibilidade de recuperar o que aconteceu. A escrita objetiva seria homogeneizante, voltada para a narrativa de uma história linear, ao passo que a subjetividade da literatura resulta em uma escrita lacunar e fragmentária, mais propensa a despertar o pathos e provocar a compaixão dos leitores."

Aporias da memória: estratégias de escrita resistente em três romances contemporâneos brasileiros, de Dayane de Oliveira Gonçalves, analisa os romances K. Relato de uma busca (2011), de Bernardo Kucinski; Não falei (2014), de Beatriz Bracher; e O corpo interminável (2019), de Claudia Lage. O ensaio parte do esclarecimento de que uma aparente contradição da narrativa de resistência em sua relação com os aspectos éticos e estéticos, se evidencia na aparência, se dissolvendo na realidade concreta e se realizando de duas formas, "as quais não necessariamente se excluem: a resistência como tema e a resistência como processo constitutivo de uma certa escrita." Nessa direção, Gonçalves discute as obras "a partir da ideia de resistência também como forma imanente da escrita, apresentada como segunda possibilidade por Bosi; ou seja, a partir de uma tensão interna (e formal) que torna tais escritas resistentes para além do tema."

Felipe Roner Vilanova Novais e Rômulo Monte Alto assinam o artigo Próxima parada: Manguetown - fluxos de cultura na cidade e um novo olhar devolvido ao Brasil, propondo 
reflexões a partir do movimento que ocorreu em Recife no final de 1980: o Manguebeat. A análise a partir dos álbuns Da lama ao caos (1994) e Afrociberdelia (1996), da banda Chico Science \& Nação Zumbi, estabelece um olhar sobre essas Cidades invisíveis (referência à Ítalo Calvino) que proporciona outros sentidos sobre o espaço e os seres que as habitam. Essas Comunidades imaginadas (referência à Benedict Anderson) refletem o espaço simbólico da Manguetown "que não se reduz a simples objetividade limitada da vida da cidade do Recife, ao mesmo tempo em que, dialeticamente, mantém essa Recife em mudança, em deslocação, injetando a energia motora necessária à atividade. Nessa articulação, reforça-se, novamente, a metáfora da parabólica no mangue, imagem da troca, da recepção e da partilha - capta Recife na lama do mangue e a transmite ao mundo, ao mesmo tempo em que recebe as ondas do mundo e injeta-as em suas entranhas, para que 'o sangue volte a circular pelas veias da Manguetown'”

Literatura e Resistência: A força da quebrada diante dos silenciamentos do campo literário problematiza a autoria e os temas abordados pela literatura brasileira, criticando as ausências e os silenciamentos impostos por uma percepção que não dialoga com a produção cultural e artística em sua amplitude. Marina Du Bois e Souza argumenta que "falar da autoria marginal, LGBT, periférica, indígena, feminina e negra é falar, sobretudo, de corpos que resistem” e desenvolve o seu estudo com base no movimento literário marginal oriundo das periferias e das margens dos grandes centros editoriais, abordando o surgimento dos saraus de literatura marginal Cooperifa em São Paulo, e do Coletivoz em Belo Horizonte.

Encerrando esta edição, Revolta nas aldeias: o conto popular francês como forma de resistência, título do artigo de Luíza Carvalho Santos Brandão e Constantino Luz de Medeiros, parte da compilação dos contos populares por Charles Perrault no ano de 1697. As Histoires ou Contes Du temps passe, avec dês moralités (Histórias ou Contos do tempo passado, com moralidades) não se constitui como referência única, apesar de sua importância e difusão na época e até a atualidade. Assim, Brandão e Medeiros selecionaram três contos para suas análises: O pequeno polegar (Charles Perrault), Jean de l'ours (anônimo) e L'enfant perdu (Paul Delaure). O artigo defende que o "conto popular evidencia uma luta de classes que, embora diferente da empreendida no seio da sociedade capitalista, se mantinha viva e constante. O triunfo do pobre sobre o rico demonstra o desejo de ruptura com a ordem vigente por parte do campesinato não apenas da França, mas de toda a Europa". Dessa forma, o conto popular francês se apresenta enquanto narrativa de resistência também por sua permanência por mais de três séculos.

Agradecemos as pesquisadoras e os pesquisadores que enviaram seus trabalhos para comporem esta edição da Revista Literatura e Autoritarismo - Literatura, música e o testemunho de resistência. A discussão que envolve a relação da literatura com a resistência é um elemento importante e vital para uma crítica literária que pensa o processo de formação cultural como algo não apenas dado, mas construído e partilhado historicamente. Os cuidados para que a crítica não se reduza a mero discurso panfletário devem estar sempre no horizonte de análises e interpretações, assim como os apagamentos e silenciamentos que impedem os artistas e os indivíduos de resistirem, comprometendo, no final de tudo, a própria existência.

\section{Elcio Loureiro Cornelsen João Luis Pereira Ourique Rosani Úrsula Ketzer Umbach - Organizadores -}

